\title{
ATIVIDADE ANTIOXIDANTE E ANTIMICROBIANA DE EXTRATO DE MALPIGHIA EMARGINATA E SUA APLICAÇÃO EM REVESTIMENTOS À BASE DE GELATINA
}

Antioxidant activity and antimicrobial extract of Malpighia emarginata and its application on gelatine-based coatings

Júlio César Rampanelli ${ }^{1}$; Paula Rossi ${ }^{1}$; Helga Cristina Fuhrmann Dinnebier ${ }^{1}$; Tauani Gabriela da Fonseca $^{1}$; Rogério Marcos Dallago ${ }^{2}$; Anildo Cunha Junior ${ }^{3}$; Rúbia Mores ${ }^{1 *}$

${ }^{1}$ Universidade do Contestado, Concórdia, SC.*E-mail: rubiamores@yahoo.com.br

${ }^{2}$ Universidade Regional Integrada do Alto Uruguai e das Missões, Erechim, RS

${ }^{3}$ Embrapa Suínos e Aves, Concórdia, SC

Data do recebimento: 09/07/2019 - Data do aceite: 01/06/2020

RESUMO: O objetivo do estudo foi investigar as atividades antioxidante e antimicrobiana do extrato de Malpighia emarginata a partir dos frutos e sua aplicação em revestimento à base de gelatina na conservação de maçã minimamente processada. A atividade antioxidante e a atividade antimicrobiana foram realizadas para o extrato de Malpighia emarginata. Diferentes tratamentos (sem adição do revestimento, com revestimento e revestimento com extrato de Malpighia emarginata) foram aplicados como métodos de conservação das maçãs minimamente processadas. $\mathrm{O}$ extrato de Malpighia emarginata apresenta atividade antioxidante de $4,34 \mu \mathrm{g} \cdot \mathrm{mL}^{-1}$ e não apresentou atividade antimicrobiana. A aplicação do extrato ao revestimento à base de gelatina não aumentou a vida de prateleira em relação à cor dos cortes de maçã.

Palavras-chave: Acerola. Maçã. Armazenamento. Minimamente processados.

ABSTRACT: The aim of the present study was to investigate antioxidant and antimicrobial activities of Malpighia emarginata extract from fruit and its application as a gelatin coating in the conservation of minimally processed apples. Antioxidant and antimicrobial activities were performed for the extract 
of Malpighia emarginata. Different treatments (without coating, with coating and coating with extract of Malpighia emarginata) were applied as conservation methods of minimally processed apples. Malpighia emarginata extract has an antioxidant activity of $4.34 \mu \mathrm{g} \cdot \mathrm{mL}^{-1}$ and presented no antimicrobial activity. Applying the extract to the gelatin coating did not increase shelf life in relation to the color of apple cuts.

Keywords: Acerola. Apple. Storage. Minimally processed.

\section{Introdução}

A crescente demanda por produtos "prontos-para-comer" e de fácil consumo estão aumentando a necessidade de melhorar o controle sobre qualidade e segurança alimentar. O processamento mínimo de frutas e hortaliças oferece ao consumidor alimentos frescos e práticos, que provocam mudanças nos hábitos alimentares das pessoas (ODRIOZOLA-SERRANO; SOLIVA-FORTUNY; MARTI'N-BELLOSO, 2008).

O processamento mínimo foi definido como a combinação de procedimentos como lavagem, triagem, descasque e corte, que não afetam a qualidade do alimento (WILEY, 1994), uma vez que frutas e vegetais frescos devem ser alimentos altamente nutritivos, convenientes e saudáveis, mantendo a frescura desejada. No entanto, como resultado do descasque, corte e preparação das frutas e hortaliças, alguns fenômenos fisiológicos, como mudanças bioquímicas e deterioração microbiológica podem resultar na degradação da cor, da textura e do sabor dos mesmos (MARTI'N-BELLOSO; SOLIVA-FORTUNY; OMS-OLIU, 2006).

Embora a vida útil de prateleira possa ser estendida com baixa temperatura $\left(<5{ }^{\circ} \mathrm{C}\right)$, tratamentos complementares para sustentar a qualidade natural das frutas, seja na preservação, processamento ou embalagem, devem ser aplicados para facilitar a distribuição e comercialização (GORNY, 2001).
A deterioração de frutas é causada principalmente pela perda de água (SORADECH et al., 2017), mudança na aparência, como textura e cor, que são atributos da qualidade de frutas que as tornam inaceitáveis para os consumidores. Assim, o uso de revestimento à base de gelatina torna-se um método que pode ser aplicado para manter a qualidade e prolongar o prazo de validade dos alimentos, por funcionar como um bloqueio para a transferência de umidade, oxigênio, sabor e/ ou aroma, aumentando, assim, a qualidade e o prazo de validade dos alimentos, sem alterar sua composição original (TONGDEESOONTORN; RAWDKUEN, 2019).

O revestimento de gelatina também pode ser usado como portador de ingredientes naturais funcionalizados, com atividade antioxidante e/ou atividade antimicrobiana, a fim de aumentar a eficácia do revestimento (HANANI; YEE; NOR-KHAIZURA, 2019). Portanto, esse sistema oferece um papel fundamental no controle do crescimento de microrganismos e no retardamento das reações oxidativas.

Neste contexto, os revestimentos comestíveis ganham importância como alternativa visando ao melhoramento e à qualidade dos produtos alimentares, protegendo-os da deterioração física, química e biológica, o que resulta em uma vida útil prolongada e segurança alimentar melhorada (SALGADO et al., 2015).

Dentre os extratos com compostos bioativos que podem ser incorporados aos revesti- 
mentos, o extrato de Malpighia emarginata é uma alternativa por ser rica em ácido ascórbico, carotenóides e composto fenólico, além de sua alta atividade antioxidante (JAESCHKE; MARCZAK; MERCALI, 2016). A acerola (Malpighia emarginata) é uma fruta nativa da América Central e do Norte. O Brasil nos últimos anos expandiu suas áreas de cultivo deste fruto, o qual é amplamente comercializado como frutas frescas, polpa e suco (RODRIGUEZ-AMAYA, 2016).

Desta forma, investigou-se a atividade antioxidante e antimicrobiana do extrato de Malpighia emarginata e aplicou-se o extrato em revestimentos, à base de gelatina, em maçãs minimamente processadas.

\section{Material e métodos}

\section{Preparação do extrato de Malpighia emarginata}

Os frutos foram adquiridos no Mercado Público de Curitiba/PR. Os extratos de Malpighia emarginata foram preparados com etanol $47 \%$ acidificado para $\mathrm{pH} 2$, usando ácido clorídrico $(2 \mathrm{M})$, sendo que a solução sólido-líquido ficou em contato por 7 dias para extração dos compostos bioativos. A solução de extração foi baseada no método proposto por Rezende, Nogueira e Narain (2017). O extrato obtido foi filtrado com papel-filtro qualitativo, com diâmetro de 70 $\mathrm{mm}$ e, depois, concentrado em evaporador rotativo à $55^{\circ} \mathrm{C}$. $\mathrm{O}$ extrato seco foi ressuspenso em água, acidificado até $\mathrm{pH} 2$, usando ácido clorídrico $(2 \mathrm{M})$, acondicionados em frascos âmbar e armazenados em um freezer $\left(-5^{\circ} \mathrm{C}\right)$.

\section{Preparo do revestimento comestível}

A gelatina comestível incolor (24 g), sem sabor, adquirida em comércio local, foi diluída em 100 mL de água fria, aguardou- -se por alguns minutos até que a gelatina absorvesse a água e, em seguida, realizou-se o aquecimento em fogo baixo até ficar pronta para uso. O extrato de Malpighia emarginata $1000 \mathrm{mg} . \mathrm{L}^{-1}$ foi misturado por gotejamento, na solução, na proporção de 1:1.

\section{Processamento mínimo das maçãs}

As maçãs prontas para consumo foram adquiridas no mercado local, sendo mantidas sob refrigeração em geladeira por $12 \mathrm{~h}$, a 8,0 ${ }^{\circ} \mathrm{C} \pm 0,5{ }^{\circ} \mathrm{C}$, afim de minimizar alterações fisiológicas. Estas foram pesadas, lavadas com água potável e sanitizadas em solução de hipoclorito de sódio, na concentração de $100 \mathrm{mg} . \mathrm{L}^{-1}$, durante $15 \mathrm{~min}$, seguidas de enxague. $\mathrm{Na}$ sequência, foram descascadas e cortadas em cubos.

Após o processamento mínimo, os cortes das maçãs foram imersos por 5 min na solução de revestimento e, em seguida, drenadas por $2 \mathrm{~min}$ para remover o excesso da solução. Os tratamentos sem revestimento e os revestidos sem e com extrato de Malpighia emarginata foram acondicionadas em bandejas de tereftalato de polietileno (PET), em porções de $100 \mathrm{~g}$ (total de 5 porções), as quais foram envoltas com filme de PVC, que ficaram armazenadas na temperatura de $8,0{ }^{\circ} \mathrm{C} \pm 0,5{ }^{\circ} \mathrm{C}$. Os controles analíticos foram retirados nos tempos zero, três e seis dias de armazenamento. Os ensaios foram realizados em triplicata para cada parâmetro determinado.

\section{Determinações analíticas}

\section{Contagem de microrganismos psicrotróficos para estimativa da vida de prateleira dos produtos}

As amostras acondicionadas foram submetidas à contagem de bactérias psicro- 
tróficas, pelo método padrão, em placas, no dia zero e no sexto dia de estocagem. Para isso, $25 \mathrm{~g}$ de cada amostra foram homogeneizadas assepticamente com $225 \mathrm{~mL}$ de água peptonada a $0,1 \%$ em stomacher, por 2 minutos. As diluições decimais foram procedidas utilizando água peptonada $0,1 \% \mathrm{e}$ o plaqueamento em superfície foi realizado utilizando $0,1 \mathrm{~mL}$ da diluição sobre o meio Plate Count Agar - PCA (CM0325, OXOID LTD, Basingstoke, Hampshire, England). As placas foram incubadas a $7{ }^{\circ} \mathrm{C} \pm 0,5^{\circ} \mathrm{C}$, por 10 dias. Os resultados foram expressos em ciclos logaritmos (log UFC.g-g ${ }^{-1}$ ). As análises foram realizadas em triplicata, conforme metodologia proposta pelo "Compendium of Methods for the Microbiological Examinations of Food (APHA, 2001).

\section{$\mathrm{pH}$}

As amostras foram homogeneizadas em liquidificador com água destilada na proporção $1: 1(\mathrm{~m}: \mathrm{m})$. O pH foi determinado através da leitura direta utilizando potenciômetro digital (DIGIMED ${ }^{\circledR}$ ).

\section{Atividade antioxidante}

A metodologia para avaliação da atividade antioxidante foi realizada pelo método espectrofotométrico descrito por Brand-Williams, Cuvelier e Berset (1995), através do monitoramento do consumo do radical livre 2,2-difenil-1-picril hidrazil (DPPH) pelas alíquotas das amostras $(100 \mu \mathrm{L})$, através da medida do decréscimo das respectivas medidas de absorbância, a $515 \mathrm{~nm}$ após 30 min de incubação. $\mathrm{O}$ ácido gálico foi o padrão comparativo utilizado nesta atividade antioxidante. A capacidade de sequestro do radical DPPH foi calculada de acordo com a equação: capacidade de sequestro de radical $\mathrm{DPPH}(\%)=\left[\left(\mathrm{A}_{0}-\mathrm{A}_{1}\right) / \mathrm{A}_{0}\right] 100$, onde $\mathrm{A}_{0}$ é a absorbância do controle e $\mathrm{A}_{1}$ é a absorbância na presença do extrato. Os resultados foram plotados em gráfico de inibição versus concentração e os valores das concentrações capazes de prover $50 \%$ de inibição $\left(\mathrm{CI}_{50}\right)$ foram estimados de acordo com a equação da curva.

\section{Atividade antimicrobiana}

A atividade antimicrobiana do extrato de Malpighia emarginata foi determinada pelo método de disco-difusão em triplicata e em placas de meio sólido. Foram utilizadas nos testes quatro cepas bacterianas: Staphylococcus aureus (BRMSA- 00210), Escherichia coli (BRMSA-0580), Pseudomonas aeruginosa (CCCD-P0003) e Salmonella senftemberg (CR-82/11). O meio de cultura utilizado para crescimento bacteriano foi o caldo de enriquecimento Brain Heart Infusion - BHI (CM1135, OXOID LTD, Basingstoke, Hampshire, England). As culturas foram suspendidas em solução salina $(0,85 \%)$ até obter turvação compatível com a escala Mac Farland 0,5 (10 UFC/mL). Em segui$\mathrm{da}$, foram semeadas uniformemente sobre a superfície da placa contendo Mueller-Hinton Agar (CM0337, OXOID LTD, Basingstoke, Hampshire, England). Foram inseridos os discos de papel-filtro com o extrato 40 g. $\mathrm{mL}^{-1}$ de Malpighia emarginata, iodo $10 \%$ (controle positivo) e etanol $47 \%$ acidificado para $\mathrm{pH} 2$, usando ácido clorídrico $(2 \mathrm{M})$ (controle negativo), sobre as placas inoculadas, que foram incubadas a $37^{\circ} \mathrm{C}$ por 24 h. Após o período de incubação, a atividade antimicrobiana foi avaliada observando a formação de halos de inibição em milímetros, com o auxílio de uma régua milimetrada e o valor considerado foi a média aritmética das triplicatas. Para o teste de difusão em disco foram considerados com atividade inibitória os halos com diâmetro $\geq 2 \mathrm{~mm}$. 


\section{Resultados e discussão}

\section{Atividade antioxidante}

Com a equação $\mathrm{y}=11,489 \mathrm{x}+0,0153$ $\left(\mathrm{R}^{2}\right.$ de 0,9988$)$ foi possível calcular a quantidade de amostra necessária para capturar (neutralizar) $50 \%$ dos radicais presentes em solução $\left(\mathrm{CI}_{50}\right)$. $\mathrm{O} \mathrm{CI}_{50}$ corresponde à quantidade de extrato necessária para reduzir o radical DPPH em 50\%; assim, quanto menor o $\mathrm{CI}_{50}$, melhor é a capacidade antioxidante do extrato. $\mathrm{O}$ extrato de Malpighia emarginata atingiu o $\mathrm{CI}_{50}$ para o radical $\mathrm{DPPH}^{*}$ com valor de $4,34 \mu \mathrm{g} \cdot \mathrm{mL}^{-1}$.

$\mathrm{O}$ valor da atividade antioxidante apresentou-se excelente ao comparar com a atividade antioxidante da Malpighia emarginata encontrada por Rezende, Nogueira e Narain (2017), $\left(\mathrm{CI}_{50}\right.$ de 10 g. $\left.\mathrm{mL}^{-1}\right)$, Rufino et al. (2010) $\left(\mathrm{CI}_{50}\right.$ de 670 e 49,2 g.g $\left.\mathrm{g}^{-1}\right)$, SOUSA (2010) $\left(\mathrm{CI}_{50}\right.$ de $308,07 \mathrm{mg} \cdot \mathrm{mL}^{-1}$ e $\mathrm{CI}_{50}$ de $386,46 \pm 1,41 \mathrm{mg} \cdot \mathrm{mL}^{-1}$ ), Pereira et al. (2013) $\left(\mathrm{CI}_{50}\right.$ de $359,42 \mu \mathrm{g} \cdot \mathrm{mL}^{-1}, 418,48 \mu \mathrm{g} \cdot \mathrm{mL}^{-1} \mathrm{e}$ $\left.471,42 \mu \mathrm{g} \cdot \mathrm{mL}^{-1}\right)$ e Klosterhoff et al. (2018) (IC $100 \mu \mathrm{g} / \mathrm{mL}^{-1}$ ).

A variação dos resultados encontrados pelos autores sobre a atividade antioxidante da Malpighia emarginata deve-se à presença de vários compostos com ação antioxidante presentes nas frutas, os quais incluem o ácido ascórbico, carotenóides e polifenóis. A quantidade e o perfil destes fitoquímicos variam em função do tipo, variedade e grau de maturação da fruta, bem como das condições climáticas e edáficas do cultivo (LEONG; SHUI, 2002).

\section{Atividade antimicrobiana}

Quatros cepas de microrganismos foram utilizadas para avaliar a atividade antibacteriana: $S$. aureus, E. coli, P. aeruginosa e $S$. senftemberg pelo teste de disco-difusão. $\mathrm{O}$ extrato não apresentou atividade antimicro- biana sobre as cepas bacterianas avaliadas.

Os ensaios de atividade antimicrobiana do extrato de Malpighia emarginata, realizados por Oliveira (2015), não apresentaram atividade antimicrobiana para a E. coli, A. hydrophila, P. aeruginosa, P. fluorescense, Salmonella spp, H. alvei, S. aureus, L. monocytogene e B. cereus. Resultado semelhante foi obtido por Delva e Goodrich-Schneider (2013) para as bactérias E. coli, S. aureus e P. putida. O extrato de Malpighia emarginata produzido por Rezende, Nogueira e Narain (2017), apresentou inibição $(\mathrm{mn})$ para as bactérias $L$. monocytogenes $(7,5 \pm 1,5 \mathrm{mn})$, E. Coli $(8,5 \pm 0,86 \mathrm{mn})$, P. aeruginosa $(9,3$ $\pm 1,53 \mathrm{mn})$ e S. cholerasuis $(7,7 \pm 1,04 \mathrm{mn})$.

\section{Revestimentos à base de gelatina e Malpighia emarginata}

Na Figura 1, apresenta-se o tempo 0, 3 e 6 dias de armazenamento das maçãs minimamente processadas sem revestimento (A), com revestimento à base de gelatina $(\mathrm{B}) \mathrm{e}$ com revestimento à base de gelatina e extrato de Malpighia emarginata (C).

Figura 1 - Maçãs minimamente processadas - A sem revestimento; $\mathrm{B}$ com revestimento à base de gelatina; $\mathrm{C}$ com revestimento à base de gelatina e extrato de Malpighia emarginata

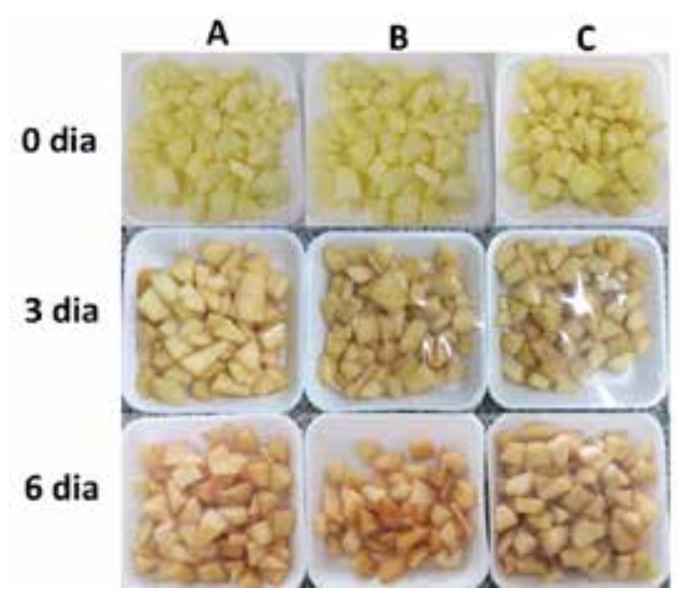


A cor é o primeiro atributo da qualidade dos alimentos avaliado pelos consumidores e é estritamente relacionado a características de qualidade como frescura, maturidade, conveniência e segurança alimentar e, portanto, um fator de classificação significativo para a maioria dos produtos alimentícios (WU; SUN, 2013).

Neste contexto, ao comparar cada um dos tratamentos, verificou-se que em todos, inclusive no controle, houve um aumento da coloração de acordo com o tempo. No tratamento com extrato de Malpighia emarginata, no dia 0 de armazenamento, uma sutil coloração foi observada no tratamento $\mathrm{C}$ (revestimento à base de gelatina e extrato de Malpighia emarginata) - esse incremento de cor ao revestimento é devido a cor escura do extrato. A partir do dia 3 de armazenamento, as maçãs minimamente processadas apresentaram uma coloração menos atrativa em relação ao grupo controle, que também teve mudança de coloração, porém menos intensa.

Os resultados indicaram que o uso de cobertura de gelatina e gelatina enriquecida com o extrato de Malpighia emarginata não foi eficiente para minimizar o escurecimento das maçãs em comparação com o tratamento sem qualquer tipo de processamento em revestimentos comestíveis.

O estudo realizado por Synowiec et al. (2014), mostra resultado com tendência inversa ao obtido neste estudo, onde a cor das maçãs revestidas apresentaram menores alterações em comparação com as maçãs não revestidas. Este fenômeno ocorre principalmente devido a uma limitação da permeabilidade ao oxigênio através do revestimento e pela atividade antioxidante incorporada no revestimento.
Em relação aos microrganismos psicrotróficos, nenhum dos tratamentos apresentou crescimento e na Tabela 1 apresenta-se a análise de $\mathrm{pH}$ das amostras, de acordo com o tempo de armazenamento.

Tabela I - Valores médios de $\mathrm{pH}$ das maçãs minimamente processadas em função dos tratamentos e dos tempos de armazenamento

\begin{tabular}{ccc}
\hline & 0 dia & 6 dias \\
\hline Sem revestimento & $4,21 \pm 0,03$ & $4,85 \pm 0,06$ \\
Com revestimento & $4,60 \pm 0,04$ & $5,38 \pm 0,33$ \\
Com revestimento e & & \\
extrato de Malpighia & $4,50 \pm 0,05$ & $5,21 \pm 0,04$ \\
emarginata & & \\
\hline
\end{tabular}

$\mathrm{O} \mathrm{pH}$ das amostras apresentaram um aumento com o tempo de armazenamento, onde as condições com maior aumento foi o tratamento com revestimento e o tratamento com revestimento e o extrato de Malpighia emarginata. $\mathrm{O}$ aumento do $\mathrm{pH}$ está relacionado com a mudança de cor, assim como a sua estabilidade durante o armazenamento. Este resultado ocorre devido à redução de ácidos orgânicos presentes na fruta, dada sua utilização como substrato respiratório, o que causa incremento nos valores de $\mathrm{pH}$ (MALACRIDA; MOTTA, 2006).

\section{Considerações finais}

O extrato de Malpighia emarginata apresentou atividade antioxidante $\left(\mathrm{CI}_{50} 4,34\right.$ $\left.\mu \mathrm{g} . \mathrm{mL}^{-1}\right)$. $\mathrm{O}$ revestimento não apresentou um aumento da vida de prateleira da maçã minimamente processada. $\mathrm{O}$ valor do $\mathrm{pH}$ foi maior quando aplicou-se o revestimento com ou sem a adição do extrato. 


\section{AGRADECIMENTOS}

Ao Fundo de Apoio à Pesquisa da Universidade do Contestado FAP/UnC pela bolsa e à estrutura física concedida pela UnC.

\section{REFERÊNCIAS}

APHA. 2001. Standard Methods for the Examination of Water and Wastewater, 22. ed. American Public Health Association, American Water Works Association, Water.

BRAND-WILLIAMS, W.; CUVELIER, M. E.; BERSET, C. Use of a free radical method to evaluate antioxidant activity. LWT - Food Science and Technology, v. 28, n.1, p. 25-30, 1995.

DELVA, L.;GOODRICH-SCHNEIDER, R. Antioxidant activity and antimicrobial properties of phenolic extracts from acerola (Malpighia emarginata DC) fruit.International Journal of Food Science and Technology, v. 48, n. 5, p. 1048-1056, 2013.

GORNY, J. A summary of CA and MA requirements and recommendations for fresh-cut (minimally processed) fruits and vegetables. Acta Horticulturae, v. 600, n.19, p. 609-614, 2001.

HANANI, Z.N.;, YEE, F.C.; NOR-KHAIZURA, M.A.R. Effect of pomegranate (Punica granatum $L$.) peel powder on the antioxidant and antimicrobial properties of fish gelatin films as active packaging. Food Hydrocolloids, v. 89, n.11, p. 253-259, 2019.

JAESCHKE, D. P.; MARCZAK, L. D. F.; MERCALI. G. D. Evaluation of non-thermal effects of electricity on ascorbic acid and carotenoid degradation in acerola pulp during ohmic heating. Food Chemistry, v. 199, p. 128-134, 2016.

KLOSTERHOFF, R. R.; BARK, J. M.; GLANZEL, N. M.; IACOMINI, M.; MARTINEZ, G. R.; WINNISCHOFER, S. M.B.; CORDEIRO, L. M. C. Structure and intracellular antioxidant activity of pectic polysaccharide from acerola (Malpighia emarginata). International Journal of Biological Macromolecules, v. 106, p. 473-480, 2018.

LEONG, L. P.; SHUI, G. An investigation of antioxidant capacity of fruit in Singapore markets. Food Chem., Washington, v.76, n.1, p.69-75, 2002.

MALACRIDA, C. R.; MOTTA, S. DA. Antocianinas em suco de uva: composição e estabilidade. Boletim do Centro de Pesquisa de Processamento de Alimentos, Curitiba, v. 24, n. 1, p. 59-82, 2006. MARTI'N-BELLOSO, O.; SOLIVA-FORTUNY, R.; OMS-OLIU, G. Fresh-cut fruits. In Y. H. Hui (Ed.), Handbook of fruits and fruit processing, p. 129-144. Oxford: Blackwell Publishing, 2006.

ODRIOZOLA-SERRANO, I.; SOLIVA-FORTUNY, R.; MARTI'N-BELLOSO, O. Effect of minimal processing on bioactive compounds and color attributes of fresh-cut tomatões. LWT - Food Science and Technology, v. 41, n.2, p. 217-226, 2008.

OLIVEIRA, B. D’ Á. Atividade Antioxidante, Antimicrobiana e Anti-Quorum Sensingde Extratos Fenólicos de Acerola (Malpighia emarginata) e Morango Silvestre (Rubus rosaefolius). 2015. Dissertação (Mestre em Saúde e Nutrição) - Universidade Federal de Ouro Preto, Ouro Preto, Mg, 2015. PEREIRA, C.T.M.; SILVA, C.R.P.; LIMA, A.; PEREIRA, D. M.; COSTA, C. N.; NETO, A.A.C. Obtenção, caracterização físico-química e avaliação da capacidade antioxidante in vitro da farinha de resíduo de acerola (Malpighia glabra L.). Acta Tecnológica, v. 8, n. 2, p. 50-56, 2013. 
REZENDE, Y. R. R. S.; NOGUEIRA, J. P.; NARAIN, N. Comparison and optimization of conventional and ultrasound assisted extraction for bioactive compounds and antioxidant activity from agro-industrial acerola (Malpighia emarginata DC) residue LWT - Food Science and Technology, v. 85, Part A, p. 158-169, 2017.

RODRIGUEZ-AMAYA, D. Acerola Juice. In: SHAHIDI, F.; ALASALVAR, C. Handbook of Functional Beverages and Human Health. Section II Fruit Juices. 1. ed. Taylor \& Francis Group, 2016, p. 85-92.

RUFINO, M. S. M.; ALVES, R. E.; DE BRITO, E. S.; PÉREZ-JIMÉNEZ, J.; SAURA-CALIXTO, F.; MANCINI-FILHO. J. Bioactive compounds and antioxidant capacities of 18 non-traditional tropical fruits from Brazil. Food Chemistry, v. 121, n. 4, p. 996-1002, 2010.

SALGADO, P. R.; ORTIZ, C. M.; MUSSO, Y. S.; DI GIORGIO, L.; MAURI, A. N. Edible films and coatings containing bioactives. Current Opinion in Food Science, v. 5, p. 86-92, 2015.

SORADECH, S.; NUNTHANID, J.; LIMMATVAPIRAT, S.; LANTANA-AND, M. Utilization of shellac and gelatin composite film for coating to extend the shelf life of banana. Food Control, v. 73, Part B, p.1310-1317, 2017.

SOUSA, M. S. B.; VIEIRA, L. M.; LIMA, A. Fenólicos totais e capacidade antioxidante in vitro de resíduos de polpas de frutas tropicais. Brazilian Journal of Food Technology, v. 14, n. 3, p. 202$210,2011$.

SYNOWIEC, A.; GNIEWOSZ, M.; KRÁSNIEWSKA, K.; PRZYBYŁ, J. L.; BACZEK, K.; WEGLAR, Z. Antimicrobial and antioxidant properties of pullulan film containing sweet basil extract and an evaluation of coating effectiveness in the prolongation of the shelf life of apples stored in refrigeration condition. Innovative Food Science \& Emerging Technologies, v. 23, p. 171-181, 2014.

TONGDEESOONTORN, W.; RAWDKUEN, S. Gelatin-Based Films and Coatings for Food Packaging Applications. Reference Module in Food Science, 2019

WILEY, R. C. Introduction to minimally processed refrigerated fruits and vegetables. In: R. C. Wiley (Ed.), Minimally processed refrigerated fruits and vegetables. p. 1-14, New York: Chapman \& Hall, 1994.

WU, D.; SUN, D. W. Colour measurements by computer vision for food quality control - A review. Trends in Food Science \& Technology, v. 29, p. 5-20, 2013. 